\section{Tamiflu reviewers respond to critics}

As authors of the Cochrane review that questions the stockpiling of the antiviral drugs Tamiflu (oseltamivir) and Relenza (zanamivir) against influenza pandemics, we wish to clarify aspects of your report on criticisms of the review (see Nature 508, 439-440; 2014).

We agree that the randomized clinical trials of Tamiflu were "not designed to test for the severe outcomes". But far from undermining our review, this is actually one of our important findings. This is because, for years, governmental bodies justified stockpiling Tamiflu (see go.nature.com/ucyjwb and go.nature.com/oi9zbg) on the basis of a short analysis of ten pooled randomized trials (L. Kaiser et al. Arch. Intern. Med. 163, 1667-1672; 2003).That study was authored by researchers at Roche, the manufacturer of Tamiflu, and concludes that the drug significantly reduces complications and hospitalizations in healthy and at-risk adults.

Our Cochrane review, by contrast, independently evaluated data from the full, previously confidential, trial-evidence base - something that officials should have done themselves. Critics of our research miss the point about what our findings say about government accountability.

You incorrectly refer to the randomized trials as "small", which would call the generalizability of the conclusions into question. In fact, trial M76001 had more than 1,400 participants, and the two pivotal studies (WV15670 and WV15671) each had more than 600 participants. You also omit to mention that the trials enrolled at-risk as well as healthy subjects.

Your report cites an observational study in which neuraminidase inhibitors (the drug class to which Tamiflu and Relenza belong) reduced mortality in hospitalized patients during the $\mathrm{H} 1 \mathrm{~N} 1$ influenza outbreak in 2009-10, apparently aligning with criticisms of our review for not including such observational studies. However, you omitted to mention the limitations of that study - or that it was funded by Roche.

We stand by our conclusion that government decisions to stockpile Tamiflu should be backed by high-quality evidence of safety and effectiveness.

Peter Doshi University of Maryland School of Pharmacy, Baltimore, Maryland, USA. pdoshi@rx.umaryland.edu Tom Jefferson The Cochrane Collaboration, Rome, Italy. The authors declare competing financial interests: see go.nature. com/wudyco for details.

\section{Prion identity wrongly credited}

The review of Stanley Prusiner's autobiography (G. Mallucci Nature 508, 180-181;2014) suggests that the idea of an infectious protein was first put forward by Tikvah Alper and colleagues (Nature 214, 764$766 ; 1967)$ and by John Stanley Griffith (Nature 215, 10431044; 1967). This perpetuates a common myth.

Alper concluded from radiation-inactivation data that the agent that causes scrapie, a neurodegenerative sheep disease, does not depend on either a nucleic acid or a protein to replicate, favouring an earlier suggestion that it might be a replicating polysaccharide.

Griffith opens his paper by crediting the idea that the scrapie agent is a protein to an earlier paper by Alper and colleagues (T. Alper et al. Biophys. Biochem. Res. Commun. 22, 278-284; 1966), and also to I. H. Pattison and K. M. Jones (Vet. Rec. 80, 2-9; 1967). In fact, this earlier Alper paper does not contain the word 'protein'. Griffith's second claim is correct. Pattison and Jones made their suggestion because the techniques they used to purify the scrapie agent were the same as those used to purify small basic proteins.

This myth probably persists because the key 1967 papers are not freely accessible online, making it harder for today's busy scientists to check their facts.

R. John Ellis University of

Warwick, Coventry, UK.

r.j.ellis@warwick.ac.uk

\section{Call for UN to act on food security}

The latest report from the Intergovernmental Panel on Climate Change (IPCC) indicates that the rise in greenhouse-gas emissions is affecting food production, particularly in poor tropical regions (see go.nature.com/ afvyfg). As director of the CGIAR Research Program on Climate Change, Agriculture and Food Security, I call for next month's session of the United Nations Framework Convention on Climate Change to act urgently on these findings (see go.nature.com/lrwfnw). Climate-change adaptation must become the priority for policymakers around the world.

The UN Food and

Agricultural Organization (FAO) has confirmed that food prices are rising sharply (see go.nature.com/yavdzo). Recent geopolitical tensions, such as the ongoing situation in Ukraine, are partly to blame, but unusual adverse weather conditions are a main culprit.

Extreme climate events such as floods, tornadoes and droughts are becoming more frequent. Yields of wheat and maize (corn) are falling; warming oceans are wreaking havoc on fish harvests; and rising sea levels threaten to wash away fertile coastal regions. As the FAO report shows, these factors are increasing global food insecurity.

Governments have been too slow to react. Research and innovation should start now because it can take up to 20 years to see results. The UN must stop procrastinating on adaptation funding, and use the IPCC and FAO reports as an impetus for action against fractured food production (see also T. MacMillan and T. G. Benton Nature 509, 25-27; 2014).

Bruce Campbell CGIAR, Copenhagen, Denmark. b.campbell@cgiar.org

\section{Ocean pollution foils search for plane}

An international search to locate missing Malaysian Airlines flight MH370, which disappeared on $8 \mathrm{March}$, is under way in the southern Indian Ocean. Various objects seen floating in the ocean and washed up on the shores of western Australia briefly raised hopes that traces of the plane had been found. Unfortunately, such litter is ubiquitous in the oceans.

Finding traces of humanity in the sea has never been easier, thanks to sophisticated technology. But finding evidence of the plane's whereabouts is proving much more difficult - despite numerous and ongoing research successes with the marineobservation systems employed (see www.ioc-goos.org).

Perhaps the tragedy of the false litter trail of flight MH370 will help to raise the public's awareness of the need to protect the oceans from pollution (see www.gpa.unep.org).

Keith Alverson United Nations Environment Program, Nairobi, Kenya.

keith.alverson@unep.org

CONTRIBUTIONS

Correspondence may be submitted to correspondence@nature. com after consulting the author guidelines at go.nature.com/cmchno. 